\title{
Penampilan Bawang Merah Pada Kawasan Rumah Pangan Lestari (KRPL) Di Pulau Punjung Kabupaten Dharmasraya
}

\section{Performance of Onion at Kawasan Rumah Pangan Lestari (KRPL) In Pulau Punjung Dharmasraya Regency}

\author{
Misran \\ Balai Pengkajian Teknologi Pertanian (BPTP) Sumatera Barat \\ Jln. Raya Padang-Solok Km 40 Sukarami, Telp 0755-31564;Fax 0755-31138
}

\begin{abstract}
To support the growth of onion plants are optimal, the price factor is one of the easiest growth factors and factors of the environment that can be modified through fertilization.The used of fertilizers with the right amount could be increased plant growth. This research aims to get the best fertilizers on the growth and yield of onion. The experiment was conducted at farmers yard members of KRPL Ranah Lintas, Pulau Punjung District, Dharmasraya Regency, from June to October 2012. The experiment was arranged in a Randomized Block Design (RBD), with involving five farmers as replication, where the sub-sample of each farmer 2 times so that the experimental units totaling 50 units. Seeds of onion used are varieties of Bima (derived from Balitsa Lembang), planted in polybags size $30 \times 35 \mathrm{~cm}$, before cutting the seedlings planted in the upper third. The treatments tasted were; (A) $0.0 \mathrm{~g} / \mathrm{pot}$ equivalent to $0 \mathrm{~kg} / \mathrm{ha}$, (B) $0.375 \mathrm{~g} /$ pot equivalent to $125 \mathrm{~kg} / \mathrm{ha}$, (C) $0.75 \mathrm{~g} /$ pot equivalent to $250 \mathrm{~kg} / \mathrm{ha}$, (D) $1,125 \mathrm{~g} /$ pot equivalent to $375 \mathrm{~kg} / \mathrm{ha}$, and (E) of $500 \mathrm{~kg} /$ ha or $1.5 \mathrm{~g} /$ pot equivalent to $500 \mathrm{~kg} / \mathrm{ha}$. As a basic fertilizer used cow manure $20 \mathrm{t}$, Urea $150 \mathrm{~kg}$, and SP36 $200 \mathrm{~kg} / \mathrm{ha}$. The results showed that no significant effect on plant height and weight of a small bulb. The highest weight bulb/pot obtained of $\mathrm{KCl}$ giving $0.375 \mathrm{~g} /$ pot with the average weight of bulb/pot $50.65 \mathrm{~g}$. The results suggested that to obtain optimal growth and yield of onion in this location (KRPL) of $\mathrm{KCl}$ should be given at a dose of $0.375 \mathrm{~g} /$ pot equivalent to $125 \mathrm{~kg} / \mathrm{ha}$.
\end{abstract}

Keywords: Onion, KRPL, $\mathrm{KCl}$

Diterima: 5-02-2014 : disetujui 10-04-2015

\section{PENDAHULUAN}

Luas lahan pekarangan di Sumatera Barat mencapai 85.141 ha yang tersebar di 12 kabupaten dan 9 kota (BPS Sumbar, 2010). Potensi yang cukup besar ini merupakan salah satu sumber potensial penyedia bahan pangan yang bernilai gizi dan memiliki nilai ekonomi tinggi.

Kementerian Pertanian melalui sebuah kegiatan pengembangan Model Kawasan Rumah Pangan Lestari (MKRPL) yaitu sebuah contoh upaya peningkatan kecukupan pangan rumahtangga secara mandiri dan berkelanjutan, mengurangi biaya konsumsi rumah tangga, dan sekaligus diharapkan dapat meningkatkan pendapatan mereka. Tujuannya adalah: (1) Memenuhi kebutuhan 

pangan dan gizi keluarga dan masyarakat melalui optimalisasi pemanfaatan pekarangan secara lestari; (2) Meningkatkan kemampuan keluarga dan masyarakat dalam pemanfaatan lahan pekarangan di perkotaan maupun perdesaan untuk budidaya tanaman pangan, buah, sayuran dan tanaman obat keluarga (toga), pemeliharaan ternak dan ikan, pengolahan hasil serta pengolahan limbah rumah tangga menjadi kompos; (3) Mengembangkan sumber benih/bibit untuk menjaga keberlanjutan pemanfatan pekarangan dan melakukan pelestarian tanaman pangan lokal untuk masa depan; dan (4) Mengembangkan kegiatan ekonomi produktif keluarga sehingga mampu meningkatkan kesejahteraan keluarga dan menciptakan lingkungan hijau yang bersih dan sehat secara mandiri.

KRPL diharapkan dapat diwujudkan menjadi sebuah model yang mampu mencarikan solusi ketahanan pangan rumahtangga secara berkelanjutan, baik di perkotaan maupun di pedesaan. Berdasarkan hasil pengamatan Badan Litbang Pertanian, perhatian petani terhadap pemanfaatan lahan pekarangan relatif masih terbatas, sehingga pengembangan berbagai inovasi yang terkait dengan lahan pekarangan belum banyak berkembang sebagaimana yang diharapkan. Pemanfaatan lahan pekarangan untuk tanaman obat-obatan, tanaman pangan, tanaman hortikultura, ternak, ikan dan lainnya, selain dapat memenuhi kebutuhan keluarga sendiri, juga berpeluang memperbanyak sumber penghasilan rumah tangga, apabila dirancang dan direncanakan dengan baik (BBP2TP, 2011).

Usaha tani bawang merah (Allium ascalonicum) merupakan salah satu jenis usaha tani sayuran yang mempunyai prospek baik terhadap upaya peningkatan pendapatan atau kesejahteraan petani di Indonesia, termasuk petani dengan kepemilikan lahan sempit. Menurut Pulitbanghorti (2011), tanaman bawang merah dapat tumbuh di dataran rendah sampai dataran tinggi (0-1000 m dpl). Untuk menunjang pertumbuhan tanaman bawang merah yang optimal, faktor hara merupakan salah satu faktor pertumbuhan dan faktor termudah dari lingkungan yang dapat dimodifikasi yakni melalui pemupukan kedalam tanah.

Banyaknya pupuk buatan yang diperlukan oleh tanaman tergantung pada jenis tanah, kultivar, iklim dan kegiatan mikrobiologis tanah. Salah satu faktor yang menyebabkan rendahnya hasil yang dicapai karena petani bawang merah masih sering mengabaikan pemupukan, bahkan ada sebagian dari mereka hanya mengandalkan kesuburan tanah, tanpa penambahan unsur hara melalui pemupukan. Hidayat dkk (1991) menyimpulkan bahwa dosis pupuk berimbang bagi bawang kultivar Sumenep sebesar $300 \mathrm{~kg} \mathrm{~N}+90 \mathrm{~kg}$ P205 + $100 \mathrm{~kg} \mathrm{K20/ha} \mathrm{dengan} \mathrm{hasil} \mathrm{umbi} \mathrm{eskip} \mathrm{sebesar} 13.2$ ton/ha .

Dilain pihak dosis pupuk ditingkatkan petani cukup tinggi menurut Hilman dkk (1990) rataan penggunaan pupuk pada tanaman bawang merah ditingkat petani adalah $200 \mathrm{~kg} \mathrm{~N}, 110 \mathrm{~kg}$ P205, 396 $\mathrm{kg} \mathrm{K} 20,337 \mathrm{~kg} \mathrm{~S}$ dan $100 \mathrm{~kg} \mathrm{Mg0/ha}$, tanpa menggunakan pupuk organik . Menurut Assandi dkk (1990), dosis pupuk yang tinggi tidak selamanya memberi manfaat terhadap pertumbuhan dan hasil bawang merah, bahkan ada kecendrungan meningkatkan susut bobot. Peneltian Hidayat dkk (1991) ada perbedaan dosis pupuk N P K yang dibutuhkan antara kultivar Sumenep dengan kultivar lainnya.

Penelitian ini bertujuan untuk mendapatkan takaran pupuk $\mathrm{KCl}$ yang terbaik terhadap pertumbuhan dan hasil tanaman bawang merah di kawasan rumah pangan lestari, Pulau Punjung Kabupaten Dharmasraya.

\section{METODE}

Penelitian dilaksanakan di pekarangan rumah anggota pelaksana kegiatan KRPL Jorong Ranah Lintas, Pulau Punjung Kabupaten Dharmasraya, dari bulan Juni sampai Oktober 2012. Percobaan disusun dalam Rancangan Acak Kelompok (RAK), dengan melibatkan sebanyak 5 orang 
petani sebagai ulangan, dimana sub sample pada masing-masing petani 2 kali sehingga unit percobaan berjumlah 50 unit. Bibit bawang merah yang digunakan yaitu varietas Bima (berasal dari Balitsa Lembang), ditanam pada polybag ukuran $30 \times 35 \mathrm{~cm}$, sebelum bibit ditanam dilakukan pemotongan $1 / 3$ pada bagian atas. Perlakuan yang diuji adalah lima takaran pupuk $\mathrm{KCl}$ yaitu; (A) $0 \mathrm{~kg} / \mathrm{ha}$ atau 0.0 g/pot, (B) $125 \mathrm{~kg} / \mathrm{ha}$ atau $0.375 \mathrm{~g} /$ pot, (C) $250 \mathrm{~kg} / \mathrm{ha}$ atau $0.75 \mathrm{~g} /$ pot, (D) $375 \mathrm{~kg} / \mathrm{ha}$ atau $1.125 \mathrm{~g} / \mathrm{pot}$, dan (E) $500 \mathrm{~kg} / \mathrm{ha}$ atau $1.5 \mathrm{~g} /$ pot. Sebagai pupuk dasar digunakan pupuk kandang sapi $20 \mathrm{t}$, Urea 150 kg, dan SP36 200 kg/ha. Pupuk kandang sapi dan SP36 diaduk rata dengan tanah 1 minggu sebelum tanam, sedangkan pupuk Urea dan $\mathrm{KCl}$ (sesuai takaran) diberikan 2 kali yaitu; pada umur 1 minggu setelah tanam (mst) dan $4 \mathrm{mst}$, masing-masing $1 / 2$ bagian. Penyiraman dilakukan setiap hari dan berakhir pada 2 minggu menjelang panen. Pengamatan dilakukan terhadap tinggi tanaman, jumlah umbi, berat umbi besar, berat umbi kecil dan berat umbi /pot. Data yang dikumpulkan kemudian dianalisis dengan analisis sidik ragam. Uji beda antar perlakuan dilakukan dengan menggunakan Duncan Multiple Range Test (DMRT).

\section{HASIL DAN PEMBAHASAN}

Hasil penelitian menunjukkan bahwa pemberian pupuk $\mathrm{KCl}$ tidak berpengaruh nyata terhadap tinggi tanaman dan jumlah umbi. Pada Tabel 1, walaupun secara statistik tidak berpengaruh nyata, akan tetapi secara angka-angka terlihat dimana tanaman tertinggi ditunjukkan pada pemberikan pupuk KCL 0,375 g/pot $(44.7 \mathrm{~cm})$ dan terendah pada tanpa pemberian pupuk KCL ( $42.9 \mathrm{~cm})$. Hal ini diduga karena ketidak seimbangan unsur hara didalam tanah. Menurut Subhan (1982), menyatakan bahwa meningkatnya tinggi tanaman dengan pemberian pupuk K, karena pupuk tersebut dapat menambah ketersediaan unsur hara di dalam tanah dan besarnya penambahan unsur hara sangat bergantung pada jenis dan takaran pupuk yang diberikan.

Tabel 1.Pengaruh pemberian pupuk $\mathrm{KCl}$ terhadap tinggi tanaman dan jumlah umbi pada tanaman bawang merah, Jorong Ranah Lintas, Pulau Punjung Kab. Dharmasraya. 2012.

\begin{tabular}{ccc}
\hline $\begin{array}{c}\text { Pupuk KCl } \\
(\mathrm{g} / \mathrm{pot})\end{array}$ & $\begin{array}{c}\text { Rataan Tinggi Tanaman } \\
(\mathrm{cm})\end{array}$ & $\begin{array}{c}\text { Rataan Jumlah Umbi } \\
(\text { buah })\end{array}$ \\
0,0 & $42,9 \mathrm{a}$ & $6,11 \mathrm{a}$ \\
0,375 & $44.7 \mathrm{a}$ & $7,44 \mathrm{~b}$ \\
0,750 & $44,6 \mathrm{a}$ & $6,49 \mathrm{a}$ \\
0,125 & $43,6 \mathrm{a}$ & $6,42 \mathrm{a}$ \\
1,500 & $43.5 \mathrm{a}$ & $6,26 \mathrm{a}$ \\
KK $(\%)$ & 7.49 & 19.92 \\
\hline
\end{tabular}

Angka pada lajur yang diikuti huruf yang sama tidak berbeda nyata pada taraf uji DMRT 5\%.

Pemberian pupuk $\mathrm{KCl}$ menunjukkan pengaruh yang nyata terhadap rataan jumlah umbi. Pada Tabel 1 terlihat bahwa jumlah umbi terbanyak diperoleh pada perlakuan pemberian $\mathrm{KCl}$ 0,375 g/pot (7,44 buah) dan terendah pada perlakuan tanpa pemberian $\mathrm{KCl}(6,11$ buah) dan diikuti oleh perlakuan lainnya. Tingginya perolehan jumlah buah per-rumpun pada perlakuan B $(0,375 \mathrm{~g} / \mathrm{pot})$ dan jumlah buah cendrung menurun bila takaran pupuk $\mathrm{KCl}$ ditingkatkan. Hal ini diduga karena pada takaran tersebut $(0,375 \mathrm{~g} / \mathrm{pot})$ unsur sudah berada pada keadaan yang seimbang. Hasil penelitian Abdulrachman dan Susanti (2004) mengatakan pemberian pupuk K dalam tanah yang cukup menyebabkan pertumbuhan tanaman lebih optimal. 
Berat umbi bawang merah dalam pertumbuhannya dipengaruhi oleh dosis pupuk $\mathrm{KCl}$ Pada Tabel 2 dapat dilihat, pemberiaan pupuk $\mathrm{KCl}$ menunjukkan pengaruh yang nyata terhadap perolehan bobot besaran umbi dan bobot umbi per-pot. Pemberiaan pupuk $\mathrm{KCl}$ 0,375 g/pot menunjukkan bobot umbi besar terberat $(11,48 \mathrm{~g})$, tidak berbeda nyata dengan pemberiaan pupuk $\mathrm{KCl} 0,750 \mathrm{~g} /$ pot $(10,40$ g). Bobot umbi besar terendah diperoleh pada perlakuan tanpa pemberian pupuk $\mathrm{KCl}$ yaitu $8,93 \mathrm{~g}$ dan berbeda tidak nyata dengan pemberian pupuk $\mathrm{KCl} 0,125 \mathrm{~g} /$ pot serta pemberian pupuk $\mathrm{KCl} 1,500$ g/pot. Sedangkan pemberian pupuk $\mathrm{KCl}$ tidak menunjukkan pengaruh yang nyata terhadap pengamatan perolehan umbi kecil/pot.

Tabel 2. Pengaruh pemberian pupuk $\mathrm{KCl}$ terhadap berat umbi pada tanaman bawang merah, Jorong Lubuk Aur, Pulau Punjung, Kabupaten Dharmasraya. 2012.

\begin{tabular}{cccc}
\hline $\begin{array}{c}\text { Pupuk KCL } \\
(\mathrm{g} / \mathrm{pot})\end{array}$ & $\begin{array}{c}\text { Rataan Berat Umbi besar } \\
(\mathrm{g})\end{array}$ & $\begin{array}{c}\text { Rataan Berat Umbi kecil } \\
(\mathrm{g})\end{array}$ & $\begin{array}{c}\text { Rataan Berat Umbi /pot } \\
(\mathrm{g})\end{array}$ \\
\hline 0,0 & $8,93 \mathrm{~b}$ & $4,30 \mathrm{a}$ & $45,05 \mathrm{a}$ \\
0,375 & $11,48 \mathrm{a}$ & $4,17 \mathrm{a}$ & $50,65 \mathrm{~b}$ \\
0,750 & $10,40 \mathrm{a}$ & $4,12 \mathrm{a}$ & $46,20 \mathrm{a}$ \\
0,125 & $9,78 \mathrm{~b}$ & $4,33 \mathrm{a}$ & $45,70 \mathrm{a}$ \\
1,500 & $8,98 \mathrm{~b}$ & $4,24 \mathrm{a}$ & $45,95 \mathrm{a}$ \\
KK $(\%)$ & 17.17 & 20.6 & 9.17 \\
\hline
\end{tabular}

Angka pada lajur yang diikuti huruf yang sama tidak berbeda nyata pada taraf uji DMRT 5\%.

Pemberian pupuk $\mathrm{KCl}$ menunjukkan pengaruh yang nyata terhadap pengamatan bobot umbi/pot. Pada Tabel 2 terlihat bahwa bobot umbi/pot terberat ditunjukkan pada pemberian $\mathrm{KCl} 0,375 \mathrm{~g} / \mathrm{pot}$ $(51,65 \mathrm{~g})$ berbeda nyata dengan perlakuan tanpa pemberian $\mathrm{KCl}(43,05 \mathrm{~g})$ dan semua perlakuan lainnya. Tingginya bobot umbi/pot yang diperoleh pada perlakuan B tersebut diduga karena unsur hara yang dibutuhkan tanaman berada dalam keadaan seimbang sehingga sudah cukup untuk meningkatkan hasil bawang merah. Assandi dkk. (1990), mengatakan dosis pupuk yang tinggi tidak selamanya memberikan mafaat terhadap pertumbuhan hasil tanaman bawang merah, bahkan ada kecendrungan meningkatkan susut bobot.

\section{KESIMPULAN}

1. Takaran pemberian pupuk $\mathrm{KCl}$ pada tanaman bawang merah berpengaruh nyata terhadap jumlah umbi, berat umbi besar, dan berat umbi perpot. Sedangkan pengamatan terhadap tinggi tanaman dan berat umbi kecil tidak berpengaruh nyata.

2. Takaran pemberian pupuk $\mathrm{KCl} 0,375 \mathrm{~g} /$ pot setara dengan $125 \mathrm{~kg} / \mathrm{ha}$ menunjukkan rataan jumlah umbi dan berat umbi perpot lebih baik yaitu 7,44 buah/pot dan 50,65 g/pot. Sedangkan pemberian pupuk $\mathrm{KCl}$ ditingkatkan perolehan jumlah umbi dan berat umbi perpot cendrung lebih rendah.

3. Untuk mendapatkan pertumbuhan dan hasil yang optimal pada tanaman bawang merah di kawasan RPL Jorong Ranah lintas, Pulau Punjung, Kabupaten Dharmasraya sebaiknya KCl diberikan pada takaran $0,375 \mathrm{~g} /$ pot setara dengan $125 \mathrm{~kg} / \mathrm{ha}$. 
Misran: Penampilan Bawang Merah Pada Kawasan Rumah Pangan Lestari (KRPL) Di Pulau Punjung

\section{UCAPAN TERIMAKASIH}

Penulis menyampaikan terima kasih kepada Ir. Atman, M.Kom yang telah membimbing dalam perencanaan, pelaksanaan, dan pelaporan kegiatan, serta penulisan karya ilmiah ini.

\section{DAFTAR PUSTAKA}

Abdulrachman, S. dan Z. Susanti. 2004. Pengaruh pemberian zeolit terhadap peningkatan efisiensi pupuk $\mathrm{P}$ dan $\mathrm{K}$ pada tanaman. Jurnal Zeolit Indonesia. 3:1-12.

Assandi, A.A. dan T. Koestoni. 1990. Effisiensi pemupukan pada pertanaman tumpang gilir bawang merah-cabai. I. Efisiensi pemupukan pada pertanaman bawang merah. Bul. Penel. Hort. 19 (1): $1-6$.

Balai Besar Pengkajian dan Pengembangan Teknologi Pertanian. 2011. Petunjuk Pelaksanaan Pengembangan Model Kawasan Rumah Pangan Lestari. Bogor

BPS Sumbar, 2010. Sumatera Barat dalam angka tahun 2009. Bappeda dan Badan Pusat Statistik Propinsi Sumatera Barat. Padang.

Hidayat,A., Yusdar Hilman, Nunung Nurtika dan Suwandi. 1991. Hasil-hasil penelitian sayuran di dataran rendah. Prosiding Lokakarya Nasional Sayuran. Badan Litbangtan, Jakarta.

Hilman, Y. dan Suwandi. 1990. Pengaruh penggunaan pupuk N dan dosis P terhadap pertumbuhan dan hasil tanaman bawang merah. Bul. Penel. Hort. Vol. 19 No. 1.

Puslibanghorti. 2011. Petunjuk teknis budidaya aneka sayuran. Pusat Penelitian dan Pengembangan Hortikultura. Badan Penelitian dan Pengembangan Pertanian. Kementerian Pertanian.

Subhan. 1982. Pengaruh Macam dan Dosis Pupuk terhadap Pertumbuhan dan Hasil Tanaman Kentang Varietas Cosima. Buletin Penelitian Hortikultura Vol. 9 No. 1. 